TITLE:

\title{
Lipase-Catalyzed Esterification of Triterpene Alcohols and Phytosterols with Oleic Acid
}

\section{AUTHOR(S):}

Kobayashi, Takashi; Ogino, Akane; Miyake, Yasuhito; Mori, Hajime; Hosoda, Asao; Fujita, Muneki; Tsuno, Takuo; Adachi, Shuji

\section{CITATION:}

Kobayashi, Takashi ... [et al]. Lipase-Catalyzed Esterification of Triterpene Alcohols and Phytosterols with Oleic Acid. Journal of the American Oil Chemists' Society 2014, 91(11): 1885-1890

\section{ISSUE DATE:}

2014-08-24

URL:

http://hdl.handle.net/2433/198297

\section{RIGHT:}

The final publication is available at Springer via http://dx.doi.org/10.1007/s11746-0142531-1; 許諾条件により本文ファイルは2015-08-24に公開.; This is not the published version. Please cite only the published version.; この論文は出版社版でありません。引用 の際には出版社版をご確認ご利用ください。 


\title{
Lipase-Catalyzed Esterification of Triterpene Alcohols and Phytosterols with Oleic Acid
}

Takashi Kobayashi, Akane Ogino, Yasuhito Miyake, Hajime Mori, Asao Hosoda, Muneki Fujita, Takuo Tsuno, Shuji Adachi*

T. Kobayashi, A. Ogino, S. Adachi*

Division of Food Science and Biotechnology, Graduate School of Agriculture, Kyoto University, Sakyo-ku, Kyoto 606-8502, Japan

E-mail: adachi@kais.kyoto-u.ac.jp

Phone: +81-75-753-6286; Fax: +81-75-753-6285

Y. Miyake, H. Mori, A. Hosoda

Industrial Technology Center of Wakayama Prefecture, 60 Ogura, Wakayama 649-6261, Japan

M. Fujita, T. Tsuno

Tsuno Food Industrial Co. Ltd., 94 Shinden, Katsuragi-cho, Ito-gun, Wakayama 649-7194, Japan

\begin{abstract}
Oleic acid esters of phytosterols (PSs) and triterpene alcohols (TAs), derived from rice bran, were synthesized using lipases under mild conditions. Some lipases, especially from Candida rugosa, type VII, showed very high substrate specificity towards both PSs and TAs, when a mixture of PS and TA (PS/TA mixture) was used as the substrate source. The maximum yield of PS esters was $c a$. $80 \%$ in each case; however, the maximum yield of TA esters was much lower when the reaction was continued for $7 \mathrm{~d}$. Due to the difficulty in purifying the esters obtained when the PS/TA mixture was used as source of substrate, free PSs and TAs were separated from the PS/TA mixture by silica-gel and reverse-phase chromatography prior to esterification. The pure PSs or TAs were esterified with oleic acid to obtain the corresponding esters with high purity. Differential scanning calorimetric (DSC) analysis of the resulting esters revealed that their melting points ranged from 7.0 to $42^{\circ} \mathrm{C}$. These values were at least $100^{\circ} \mathrm{C}$ lower than those of the free PSs and TAs.
\end{abstract}

Keywords Esterification, Lipase, Oleic acid, Phytosterol, Triterpene alcohol

\section{Introduction}

In the recent years, ferulic acid has attracted attention as a natural anti-oxidant [1, 2]. Ferulic acid 
links with phytosterol (PS) or triterpene alcohol (TA) through an ester bond and exists as $\gamma$-oryzanol in rice bran [2, 3]. Therefore, during large-scale ferulic acid production from rice bran, a mixture of phytosterol and triterpene alcohol (PS/TA mixture) is formed. Three kinds of PSs and two kinds of TAs have been reported to constitute the PS/TA mixture [4]. However, they have not been used effectively.

PSs act to decrease blood cholesterol and LDL cholesterol concentrations [5, 6]; many studies have been performed with the purpose of their application in food. It has been also reported that PSs have surface activity and improve the stability of emulsions [7, 8]. Furthermore, PSs contribute to the recovery of the barrier function of skin [9], and TAs have anti-inflammatory activity [10]. Therefore, PSs and TAs have been explored as raw materials for food and cosmetics.

However, the use of PSs and TAs is limited at present due to their high melting point and low solubility, both in oil and water. Therefore, esterification of PSs and TAs with fatty acids has been performed to lower their melting point and improve their solubility in oil. However, chemical synthesis of the esters would cause side reactions. Recent work has focused on lipase-catalyzed synthesis of esters from the viewpoint of the mild reaction conditions and high selectivity, thus preventing side reactions. In this study, we applied the lipase-catalyzed reaction to the synthesis of oleic acid esters of PSs and TAs. We evaluated the substrate specificity for PSs and TAs and screened for lipases suitable for the synthesis of PS and TA esters. In addition, differential scanning calorimetric (DSC) analysis was performed to evaluate the properties of the esters.

\section{Materials and methods}

\section{Materials}

Nineteen kinds of lipases, mainly from microorganisms, were obtained from Sigma-Aldrich Japan (Tokyo, Japan), Meito Sangyo (Aichi, Japan), Amano Enzyme (Aichi, Japan), or Nagase ChemteX (Osaka, Japan) as shown in Table 1. A mixture of phytosterols and triterpene alcohols (PS/TA mixture) was obtained as a by-product during ferulic acid production from rice bran. PS and TA contents in the PS/TA mixture was ca. 57\% based on TLC-FID analysis. Oleic acid (purity, >99\%) was purchased from Tokyo Chemical Industry (Tokyo, Japan). All other chemicals were obtained from Wako Pure Chemical Industries (Osaka, Japan).

\section{(Table 1 is here.)}

\section{Substrate specificity of lipases for PS and TA}

The PS/TA mixture (270 mg) was dissolved in oleic acid $\left(530 \mathrm{mg}\right.$ ) at $30^{\circ} \mathrm{C}$, where the molar ratio of PS and TA in the PS/TA mixture to oleic acid was 1:5. Lipase was dissolved in distilled water at the enzyme concentration of $2000 \mathrm{U} / \mathrm{mL}$, where the activity of the lipase was defined as $1 \mathrm{U}$ when it 
liberated $1 \mu \mathrm{mol}$ of free fatty acid/min during the hydrolysis of olive oil. The lipase solution (200 $\mu \mathrm{L}$ ) was added to the PS/TA mixture and oleic acid. The mixture was vigorously stirred by a magnetic stirrer at $30^{\circ} \mathrm{C}$. After $24 \mathrm{~h}$ of the reaction period had elapsed, $10 \mathrm{~mL}$ of 2-propanol was added and the mixture was analyzed by HPLC.

\section{HPLC analysis}

Composition of the PS/TA mixture and progress of the esterification were measured by HPLC. For the measurement of the PS/TA mixture containing free PSs and TAs, the PS/TA mixture (ca.10 mg) was dissolved in $1 \mathrm{~mL}$ of 2-propanol. The solution was injected into Cosmosil $5 \mathrm{C}_{18}$-MS-II or Cosmosil Cholester HPLC columns $(3 \times 150 \mathrm{~mm}$, Nacalai Tesque, Kyoto, Japan) connected to an HPLC pump, LC-10ADVP (Shimadzu, Kyoto, Japan), and a UV detector, SPD-10AVVP (Shimadzu). Elution was performed at $0.4 \mathrm{~mL} / \mathrm{min}$ with $98 \%$ methanol for the Cosmosil 5C 18 -MS-II column and with methanol for the Cosmosil Cholester column. Detection was at UV $205 \mathrm{~nm}$.

For the measurement of the reaction progress, portion of the reaction mixture ( $c a .100 \mathrm{mg}$ ) was appropriately (ca. 10 times) diluted with 2-propanol. The solution was injected into the above mentioned HPLC system with the Cholester column. Elution was performed at $0.4 \mathrm{~mL} / \mathrm{min}$ with the mixture of 2:1 (v/v) 2-propanol:methanol. Detection was at UV $205 \mathrm{~nm}$.

\section{Esterification of crude PS and TA}

Two esterification procedures were examined to obtain products for structural identification. In the first, PS and TA in the PS/TA mixture (crude PS and TA) were esterified with oleic acid and the esters of PSs and TAs were separated by chromatography. In the second method, purification of PSs and TAs from the PS/TA mixture was performed prior to esterification, which was done using the resulting pure PS or TA.

In the first method, oleic acid was mixed with the PS/TA mixture at a molar ratio of PS/TA to oleic acid of 1:5. An aqueous solution of lipase (2000 U/mL, $1 \mathrm{~mL}$ ) was added to $4 \mathrm{~g}$ of the mixture, which was then vigorously stirred by a magnetic stirrer at $30^{\circ} \mathrm{C}$. At appropriate intervals, an aliquot (ca. $50 \mathrm{mg}$ ) of the sample was taken and analyzed by HPLC.

\section{Esterification of purified PS and TA}

Free PSs and TAs were purified from the PS/TA mixture prior to esterification using silica-gel and reverse-phase chromatography. The PS/TA mixture (5 g) was roughly separated into PS- and TA-containing fractions by silica-gel chromatography (column size: $37 \times 300 \mathrm{~mm}$ ) using a VSP-2050 pump (Tokyo Rika Kikai, Tokyo, Japan) with $14 \mathrm{~mL} / \mathrm{min}$ of 90:10 (v/v) hexane/ethyl acetate as eluent. The resulting fractions containing PSs or TAs were condensed and further purified by HPLC. A portion of the condensed fraction (ca. $40 \mathrm{mg}$ ) was dissolved in $1 \mathrm{~mL}$ acetone and 
injected into a Cosmosil Cholester HPLC column $(20 \times 250 \mathrm{~mm}$, Nacalai Tesque $)$ connected to the above described HPLC system. Elution was performed with methanol at $8 \mathrm{~mL} / \mathrm{min}$ and detection was at $205 \mathrm{~nm}$.

Esterification of pure PS or TA was then performed as follows. Purified PS or TA (23-48 mg) was dissolved in oleic acid ( $0.6 \mathrm{~g}$ ), and $0.5 \mathrm{~mL}$ of lipase solution from Candida rugosa (type VII, Sigma, $2000 \mathrm{U} / \mathrm{mL}$ ) was added to the mixture. This was vigorously stirred at $30^{\circ} \mathrm{C}$ for $10 \mathrm{~d}$. After the reaction was complete, PS- and TA esters were roughly purified individually from the oil phase of the reaction mixture by a Sep-Pak Silica Plus cartridge (Nihon Waters, Tokyo, Japan) with 80:20 (v/v) hexane/ethyl acetate as eluent. The crude esters were further purified by a Cosmosil Cholester HPLC column $(20 \times 250 \mathrm{~mm}$, Nacalai) with 2:1 (v/v) 2-propanol/methanol as eluent. Other conditions for HPLC were the same as described above.

Mass spectrometry analysis of PS and TA was performed separately by LC-MS (ESI; Exactive, Thermo Fisher Scientific, Kanagawa, Japan). NMR analysis of free PS/TA and their esters was performed in $\mathrm{CDCl}_{3}$ using Avance 400 (400 MHz, Bruker Japan, Kanagawa, Japan). Infrared analysis of the esters was performed using an FTIR-8300 spectrophotometer (Shimadzu).

\section{Differential scanning calorimetric analysis}

Differential scanning calorimetric (DSC) analysis of the esters was performed using DSC 6200R (Hitachi High-Tech Science, Tokyo, Japan). The ester (2-3 mg) was placed in an aluminum sample pan. Temperature program consisted of the following: First, the sample was heated from $30^{\circ} \mathrm{C}$ to $100^{\circ} \mathrm{C}$ at $10^{\circ} \mathrm{C} / \mathrm{min}$ and maintained isothermally for 2 min to completely melt the sample, and then cooled to $-50^{\circ} \mathrm{C}$ at $5^{\circ} \mathrm{C} / \mathrm{min}$ and maintained isothermally for $2 \mathrm{~min}$. The sample was then heated again to $100^{\circ} \mathrm{C}$ at $10^{\circ} \mathrm{C} / \mathrm{min}$. The second heating cycle was recorded for the DSC analysis, and measurements were performed in triplicate.

\section{Results and Discussion}

\section{Separation and identification of free PS and TA}

Figure 1 shows the HPLC chromatograms for the analysis of the PS/TA mixture obtained from two different types of reverse-phase columns (Cosmosil 5C 18 -MS-II (ODS column) and Cosmosil Cholester (Cholester column)). Three peaks corresponding to PSs and TAs were observed when the ODS column was used with $98 \%$ methanol as eluent (Fig. 1A). The peaks were not completely separated because the structures of PSs and TAs are similar. However, five peaks were observed when a Cholester column was used (Fig. 1B). Therefore, it is more appropriate to use a Cholester column to analyze the PS/TA mixture.

(Figure 1 is here) 
For structural identification, free PSs and TAs were purified from the PS/TA mixture by silica-gel and reverse-phase chromatography using the Cholester column. Molecular masses for PS-1, PS-2, PS-3, TA-1, and TA-2 were respectively estimated to be 400, 400, 414, 426 and 440 by LC-MS. The structures of each PS and TA was confirmed using NMR by comparing with previous reports [4]: PS-1 and PS-2 were either campesterol or 22-dihydrobrassicasterol; PS-3, TA-1 and TA-2 were $\beta$-sitosterol, cycloartenol, and 24-methylenecycloartanol, respectively (Scheme 1).

\section{(Scheme 1 is here)}

As shown in Figure 1B, TAs were eluted faster than PSs. The Cholester column has a cholesteryl group on its stationary phase and can recognize a plane structure of a molecule better than a normal ODS column. TA-1 and TA-2, both have a cyclopropane ring and would be more bulky than PSs. Therefore, interactions between TAs and the cholesteryl group would be weaker than those for PSs, resulting in the shorter retention time for TAs.

\section{Substrate specificity of lipase}

To evaluate the substrate specificity of lipases toward PSs and TAs, esterification of the PS/TA mixture with oleic acid at the molar ratio of 1:5 was performed using 19 different lipases. Most of the lipases showed higher substrate specificity toward PSs than TAs (Table 1). Especially, lipases from C. rugosa showed the highest yield at $24 \mathrm{~h}$ (ca. 80\% for PSs). When lipases from Burkholderia cepacia and Penicillium camembertii were used, the yield ranged from 30 to $70 \%$. On the other hand, some lipases showed lower substrate specificity toward both PSs and TAs (yield $\leq 10 \%$ ). From these results, the lipase from C. rugosa was the best candidate for PS ester production.

There was a difference between the esterification yield for TAs when four types of the lipases from C. rugosa were used. The yield for TAs was low when Lipase OF was used, which is reported to contain only one isozyme [11]. On the other hand, lipase from C. rugosa, type VII, and Lipase AY "Amano" 30G contain isozymes. Therefore, the isozymes, absent in Lipase OF, exhibited stronger esterification activity with TAs. From these results, lipase from C. rugosa, type VII, which showed higher specific activity with effective esterification of TAs, was used in this study.

\section{Esterification of PS and TA}

To perform the esterification process efficiently, it is necessary to decrease the total volume by decreasing the amount of oleic acid added. Therefore, we performed esterification of PSs and TAs in the PS/TA mixture by changing the molar ratio of PS/TA:oleic acid from 1:1 to 1:7. When the proportion of oleic acid was smaller (PS/TA:oleic acid $=1: 1$ or $1: 3$ ), the yield decreased probably due to incomplete dissolution of PS/TA or insufficient stirring due to high viscosity of the reaction mixture. On the other hand, the reaction proceeded faster with higher yield (80-85\%) when the molar ratio of PS/TA to oleic acid was 1:5 or 1:7. In addition, the final yield of the esters was not 
greatly different when the molar ratio was $1: 5$ or 1:7. Therefore, the optimum molar ratio of PSs/TAs to oleic acid was 1:5 in this study.

Figure 2 shows the time course for the esterification of PSs and TAs in the PS/TA mixture. Esterification of PSs was faster and reached equilibrium within $1 \mathrm{~d}$. On the other hand, esterification of TAs was much slower. In addition, lipase showed almost the same substrate specificity towards all PSs (PS-1 to -3). This was also true for TAs (TA-1 and -2); conversely, both TA-1 and TA-2 were esterified slowly. Therefore, the presence of a cyclopropane ring in TAs strongly affected substrate specificity.

Next, we tried to purify PS esters and TA esters from the reaction mixture. However, peaks in the HPLC chromatogram corresponding to the PS esters and TA esters could not be separated when the PS/TA mixture was esterified with oleic acid. Therefore, another method was introduced. We performed the esterification of PSs and TAs, which were purified from the PS/TA mixture by silica gel chromatography, instead of using the PS/TA mixture as the source of free PSs and TAs. By silica gel chromatography from the PS/TA mixture, we obtained two products: a mixture of PSs (PS-1 to -3) and another of TAs (TA-1 and -2). These mixtures were separately esterified with oleic acid, and the resultant PS and TA esters were purified. Although the free PSs were well separated by HPLC, as shown in Figure 1B, their oleic acid esters could not be separated. The same phenomenon was observed for the mixture of TAs. This could be since esterification of free PSs or TAs decreases the flatness of the molecular structure, resulting in a change in the interactions between esters and the stationary phase of the Cholester column.

Therefore, to obtain products for structural identification, the following procedures were required: (1) Separation of free PSs and TAs from the PS/TA mixture by silica gel chromatography, (2) purification of each free PS and TA by HPLC using a Cholester column, (3) esterification, and finally (4) purification of the resulting esters by HPLC. Thus, we synthesized oleic acid esters of PSs and TAs and then analyzed the purified esters by NMR and IR. In the ${ }^{1} \mathrm{H}-\mathrm{NMR}$ spectra of free PSs and their esters, peaks of the geminal proton on the carbon atom, to which hydroxyl group attaches, shifted from $3.5 \mathrm{ppm}$ to $4.6 \mathrm{ppm}$ by esterification (Suppl. figs. 1-3). In addition, the IR spectra of the PS esters showed a strong absorption peak at $c a .1735 \mathrm{~cm}^{-1}$, which corresponded to $\mathrm{C}=\mathrm{O}$ double bond stretching and also meant the presence of an ester bond (Suppl. figs. 6-8). The same results were observed in the spectra for all free TAs and their corresponding esters (Suppl. figs. 4, 5, 9 and 10). Therefore, all PSs and TAs were esterified with oleic acid (Scheme 1). However, we could not distinguish PS-2 ester from PS-3 ester based on these spectra.

\section{Differential scanning calorimetric analysis of the esters}

In the DSC analysis with temperature increasing from $-40^{\circ} \mathrm{C}$ to $80^{\circ} \mathrm{C}$, a large difference was observed between PS esters and TA esters (Fig. 3). When PS esters were analyzed, an exothermic 
peak due to crystallization was observed for PS- 1 and PS-3 esters at $5^{\circ} \mathrm{C}$ and $-9^{\circ} \mathrm{C}$, respectively. An endothermic peak due to phase transition from crystal to liquid crystal was also observed for PS-1 ester at $23^{\circ} \mathrm{C}$. Furthermore, a strong endothermic peak with the melting was observed in the range of $28-42^{\circ} \mathrm{C}$ (Table 2). On the other hand, only a small endothermic peak was observed at 7.0 or $14^{\circ} \mathrm{C}$ due to the melting of TA esters, and another remarkable peak was not recognized in the analysis of TA esters. From these results, it can be considered that TA esters are the compounds that hardly crystallize. In addition, the melting points of TA esters were lower than those of PS esters.

We then compared the melting points of PS and TA esters with those of free PSs and TAs. Melting points of free PSs and TAs range from $114^{\circ} \mathrm{C}$ to $160^{\circ} \mathrm{C}$ [12-18]; however, we found that the melting points considerably fell to $7.0-42^{\circ} \mathrm{C}$ after esterification with oleic acid. From these results, esterification caused a decrease in the melting points of PSs and TAs by more than $100^{\circ} \mathrm{C}$.

\section{Conclusion}

Lipase-catalyzed synthesis of PS and TA oleoyl esters was successfully preformed under mild conditions. During synthesis, there was a difference in the substrate specificity of lipase towards PSs and TAs. DSC analysis revealed that the melting points of the esters were much lower than those of free PSs and TAs. Therefore, esters would be useful as ingredients in the preparation of cosmetics.

\section{Acknowledgement}

This study was financially supported by Project Support R\&D of the Innovative Industry Technology, Wakayama Prefecture, Japan.

\section{References}

1. Graf E (1992) Antioxidant Potential of Ferulic Acid. Free Radic Biol Med 13:435-448

2. Kikuzaki H, Hisamoto M, Hirose K, Akiyama K, Taniguchi H (2002) Antioxidant Properties of Ferulic acid and its Related Compounds. J Agric Food Chem 50: 2161-2168

3. Xu Z, Godber JS (1999) Purification and Identification of Components of $\gamma$-Oryzanol in Rice Bran Oil. J Agric Food Chem 47:2724-2728

4. Yasukawa K, Akihisa T, Kimura Y, Tamura T, Takido M (1998) Inhibitory Effect of Cycloartenol Ferulate, a Component of Rice Bran, on Tumor Promotion in Two-Stage Carcinogenesis in Mouse Skin. Biol Pharm Bull 21:1072-1076.

5. Peterson DW (1951) Effect of Soybean Sterols in the Diet on Plasma and Liver Cholesterol in 
Chicks. Proc Soc Exp Biol Med 78:143-147

6. Pollak OJ (1953) Reduction of Blood Cholesterol in Man. Circulation 7: 702-706.

7. Folmer BM (2003) Sterol Surfactants: from Synthesis to Applications. Adv Colloid Interface Sci 103:99-119

8. Hoppe U, Larsson K (1981) Water-in-Oil Emulsions - A Study of Wool-Wax Alcohol-Systems. J Dispersion Sci Technol 2:433-441

9. Puglia C, Bonina F (2008) In vivo Spectrophotometric Evaluation of Skin Barrier Recovery after Topical Application of Soybean Phytosterols. J Cosmet Sci 59:217-224

10. Akihisa T, Yasukawa K, Yamaura M, Ukiya M, Kimura Y, Shimizu N, Arai K (2000) Triterpene Alcohol and Sterol Ferulates from Rice Bran and their Anti-Inflammatory Effects. J Agric Food Chem 48:2313-2319

11. Chang RC, Chou SJ, Shaw JF (1994) Multiple Forms and Functions of Candida rugosa Lipase. Biotechnol Appl Biochem 19:93-97

12. Fernholz E, MacPhillamy HB (1941) Isolation of a New Phytosterol: Campesterol. J Am Chem Soc 63:1155-1156

13. Hircher HW, Rosenstein FU (1973) Isolation of Brassicasterol from Steam Deodorizer Distillate of Rapeseed Oil: Some Properties of its Acetate Tetrabromide and its Reduction to 22, 23-dihydrobrassicasterol. Lipids 8:453-458

14. Kircher HW, Rosenstein FU (1973) Purification of Sitosterol. Lipids 8:97-100.

15. Nishioka I, Ikekawa N, Yagi A, Kawasaki T, Tsukamoto T (1965) Studies on the Plant Sterols and Triterpenes. II. Separation of Stigmasterol, $\beta$-Sitosterol and Campesterol, and about so-called “ $\gamma$-Sitosterol”. Chem Pharm Bull (Tokyo) 13:379-384

16. Li J, Ho C-T, Li H, Tao H, Tao L (2000) Separation of Sterols and Triterpene Alcohols from Unsaponifiable Fractions of Three Plant Seed Oils. J Food Lipid 7:11-20

17. Bentley HR, Henry JA, Irvine DS, Spring FS (1953) Triterpene Resinols and Related Acids. Part XXVIII. The Non-Saponifiable Fraction from Strychnos nux-vomica Seed Fat: the Structure of Cycloartenol. J Chem Soc 3673-3678

18. Starratt AN (1966) Triterpenoid Constituents of Euphorbia cyparissias. Phytochem 5:1341-1344 
Table 1 Lipase screening for the esterification of PSs and TAs.

\begin{tabular}{|c|c|c|c|c|c|}
\hline \multirow{2}{*}{ Lipase } & \multirow{2}{*}{ Origin } & \multirow{2}{*}{ Manufacturer } & \multirow{2}{*}{$\begin{array}{l}\text { Specific } \\
\text { activity } \\
(\mathrm{U} / \mathrm{mg})^{a}\end{array}$} & \multicolumn{2}{|c|}{ Yield at 24 h (\%) } \\
\hline & & & & PS esters & TA esters \\
\hline $\begin{array}{l}\text { Lipase from C. rugosa, } \\
\text { type VII }\end{array}$ & Candida rugosa & Sigma-Aldrich & 41.7 & 81.2 & 16.0 \\
\hline Lipase MY & Candida rugosa & Meito Sangyo & 13.8 & 79.9 & 22.0 \\
\hline Lipase AY "Amano" 30G & Candida rugosa & Amano Enzyme & 6.3 & 79.8 & 17.5 \\
\hline Lipase OF & Candida rugosa & Meito Sangyo & 183 & 79.5 & 9.9 \\
\hline Lipase SL & Burkholderia серасіа & Meito Sangyo & 5.0 & 67.5 & 9.6 \\
\hline Lipase G "Amano" 50 & Penicillium camembertii & Amano Enzyme & 3.8 & 30.3 & 6.1 \\
\hline Lipase TL & Pseudomonas stutzeri & Meito Sangyo & 4.6 & 10.5 & 1.5 \\
\hline Lipase PS "Amano" & Burkholderia серасіа & Amano Enzyme & 17.1 & 10.2 & 1.6 \\
\hline Lipase PL & Alcaligenes sp. & Meito Sangyo & 17.9 & 9.7 & 2.1 \\
\hline Lipase QLM & Alcaligenes sp. & Meito Sangyo & 33.3 & 7.0 & 1.7 \\
\hline Lipase QL & Alcaligenes sp. & Meito Sangyo & 16.7 & 2.8 & 0.6 \\
\hline Lipase A "Amano" G & Aspergillus niger & Amano Enzyme & 2.5 & 1.4 & 2.5 \\
\hline Lipase R "Amano" G & Penicillium roqueforti & Amano Enzyme & 0.8 & 1.2 & 0.4 \\
\hline Lipase from $R$. oryzae & Rhizopus oryzae & Sigma-Aldrich & 9.5 & 0.8 & 0.4 \\
\hline Lipase F-AP15 & Rhizopus oryzae & Amano Enzyme & 46.7 & 0.6 & 0.4 \\
\hline Lipase AL & Achromobacter sp. & Meito Sangyo & 8.8 & 0.6 & 0.3 \\
\hline Lipase M “Amano” 10 & Mucor javanicus & Amano Enzyme & 2.9 & 0.4 & 0.2 \\
\hline Lipase AF-2 & Rhizopus japonicus & Nagase Chemtex & 0.8 & 0.4 & 0.2 \\
\hline sLipase, type II & Porcine pancreas & Sigma-Aldrich & 2.5 & 0.0 & 0.0 \\
\hline
\end{tabular}

${ }^{a}$ The definition of unit (U) is as follows: $1 \mathrm{U}$ of lipase liberates $1 \mu \mathrm{mol}$ of free fatty acid $/ \mathrm{min}$ in hydrolysis of olive oil.

Table 2 Melting points for PSs, TAs, and their esters.

\begin{tabular}{ccc}
\hline \multirow{2}{*}{ Compound } & \multicolumn{2}{c}{ Melting point $\left[{ }^{\circ} \mathrm{C}\right]$} \\
\cline { 2 - 3 } & Free alcohol & Oleate $\left(T_{\mathrm{p}}\right)$ \\
\hline Campesterol (PS-1 or PS-2) $^{a}$ & $157-160^{[12,15,16]}$ & 36,42 \\
22-Dihydrobrassicasterol (PS-2 or PS-1) & $158-160.5^{[12,13]}$ & 28 \\
$\beta$-Sitosterol (PS-3) & $136-140^{[14,16]}$ & 7.0 \\
Cycloartenol (TA-1) & $114-115^{[16,17]}$ & 14 \\
24-Methylenecycloartanol (TA-2) & $118-122^{[16,18]}$ & \\
\hline
\end{tabular}

${ }^{a}$ Differentiation between PS-1 and -2 cannot be determined based on NMR analysis. 


\section{Figure legends}

Figure 1. HPLC chromatograms for the analysis of the PS/TA mixture by (A) a Cosmosil 5C 18 -MS-II column, and (B) a Cosmosil Cholester column.

Figure 2. Time course for the esterification of free PSs and TAs in the PS/TA mixture with oleic acid. The molar ratio of PS/TA to oleic acid was 1:5. Symbols represent each PS ester or TA ester as follows: $(\triangle)$ PS-1 ester, $(\diamond)$ PS-2 ester, $(\bigcirc)$ PS-3 ester, $(\mathbf{\Delta})$ TA-1 ester, $(\mathbf{O})$ TA-2 ester.

Figure 3. DSC curves obtained from melting oleic acid esters of (A) PS-1, (B) PS-2, (C) PS-3, (D) TA-1, and (E) TA-2.

Scheme 1. Structures of synthesized esters. Differentiation between PS-1 and -2 cannot be determined based on NMR analysis.

Supplemental figure 1. ${ }^{1} \mathrm{H}$ NMR spectra of free PS-1 and its oleic acid ester

Supplemental figure 2. ${ }^{1} \mathrm{H}$ NMR spectra of free PS-2 and its oleic acid ester

Supplemental figure 3. ${ }^{1} \mathrm{H}$ NMR spectra of free PS-3 and its oleic acid ester

Supplemental figure $4 .{ }^{1} \mathrm{H}$ NMR spectra of free TA-1 and its oleic acid ester

Supplemental figure $5 .{ }^{1} \mathrm{H}$ NMR spectra of free TA-2 and its oleic acid ester

Supplemental figure 6. IR spectrum of PS-1 oleic acid ester

Supplemental figure 7. IR spectrum of PS-2 oleic acid ester

Supplemental figure 8. IR spectrum of PS-3 oleic acid ester

Supplemental figure 9. IR spectrum of TA-1 oleic acid ester

Supplemental figure 10. IR spectrum of TA-2 oleic acid ester 


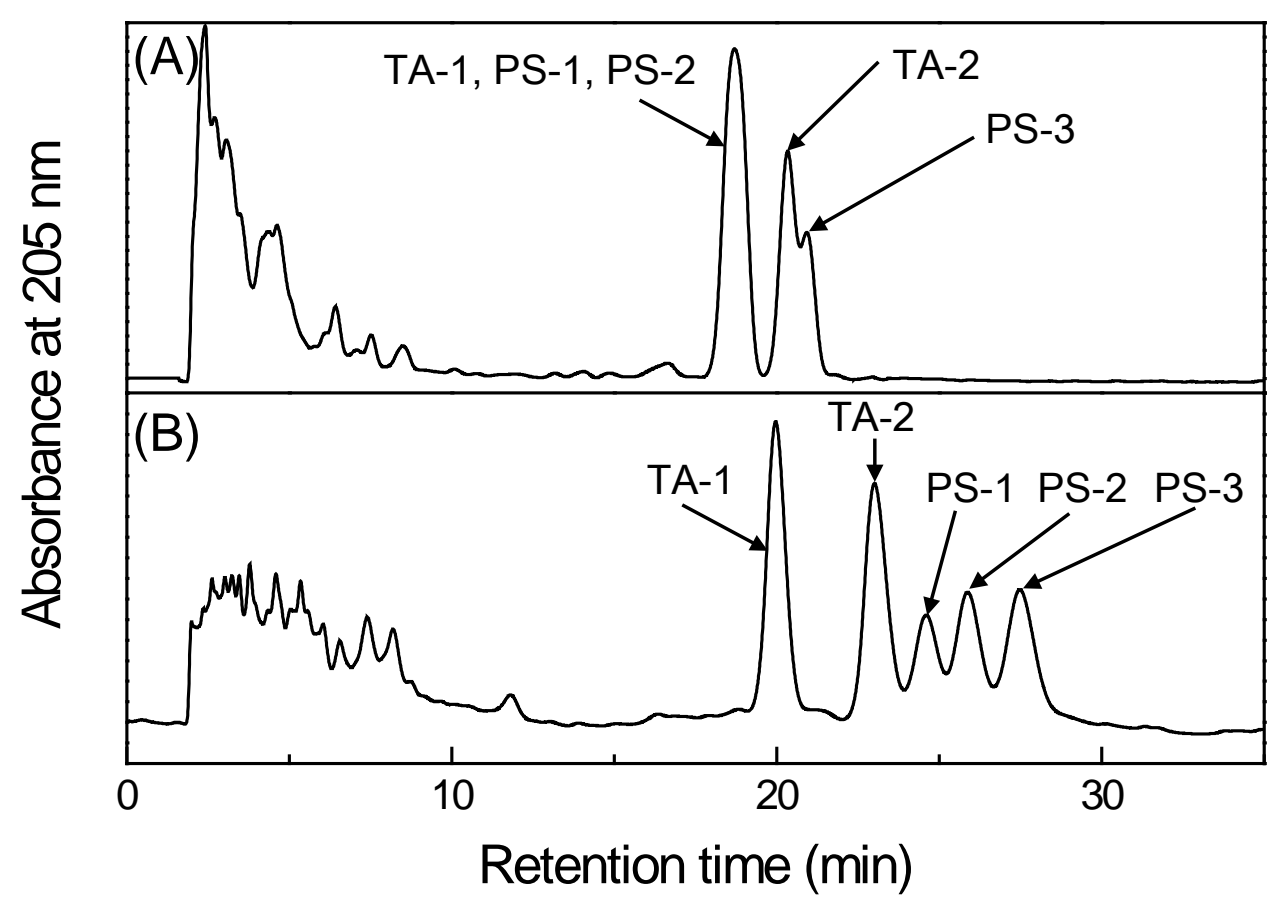

Fig. 1.

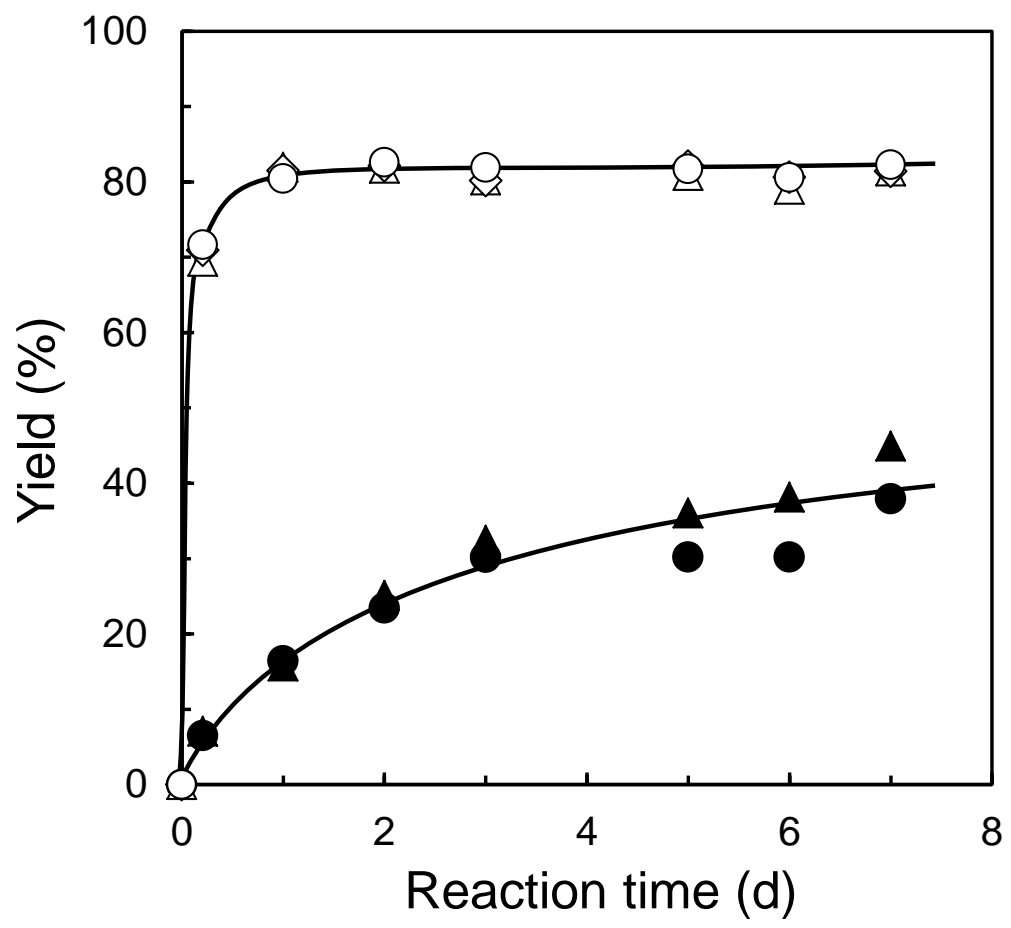

Fig. 2. 


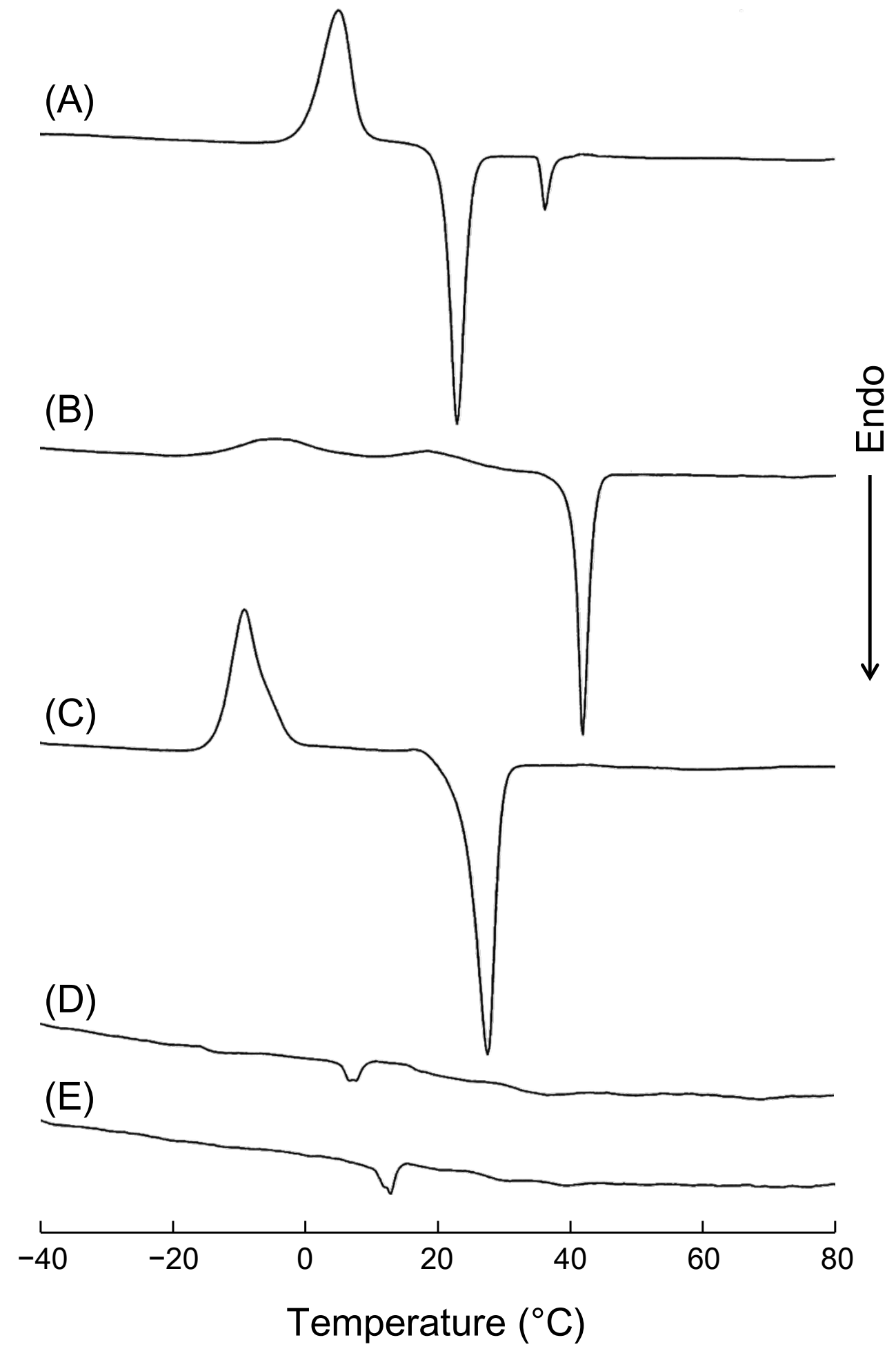

Fig. 3. 


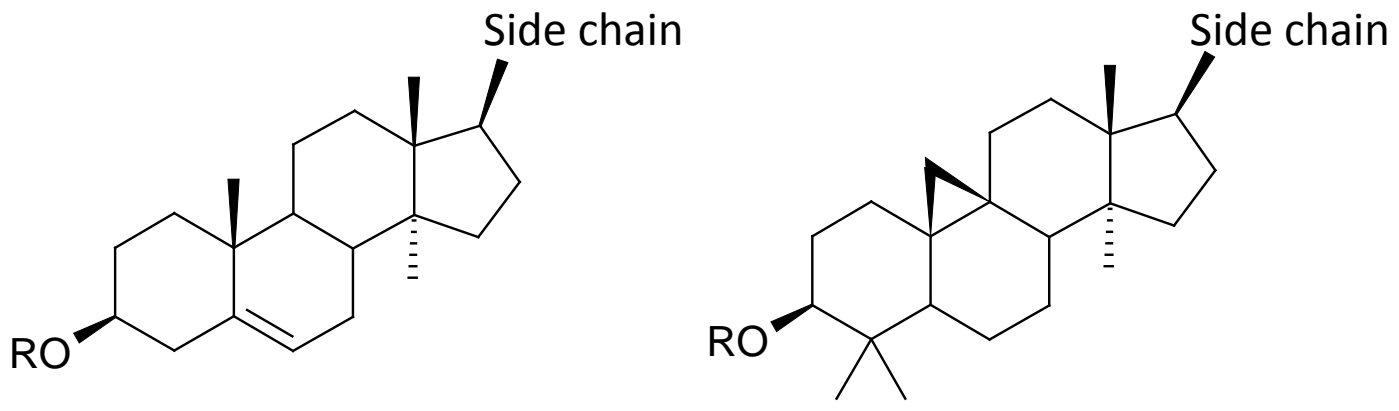

Phytosterols (PSs)

Triterpene alcohols (TAs)

Free PSs or TAs: $\mathrm{R}=\mathrm{H}$ Oleoyl esters: $\mathrm{R}=\mathrm{MM}_{\mathrm{M}}$

Side chain

Campesterol

(PS-1 or PS-2)<smiles>CC(C)CCC(C)C(C)C</smiles>

22-Dihydrobrassicasterol (PS-2 or PS-1)<smiles>CC(C)CCC(C)C(C)C</smiles>

$\beta$-Sitosterol (PS-3)<smiles>CCC(CCC(C)C)C(C)C</smiles>

Cycloartenol (TA-1)<smiles>CC(C)=CCCC(C)C</smiles>

24-Methylenecycloartanol (TA-2)

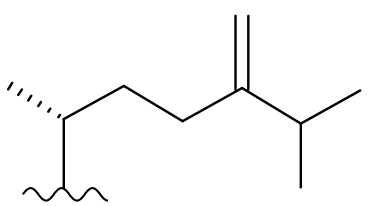

Scheme 1. 


\section{Free PS-1}
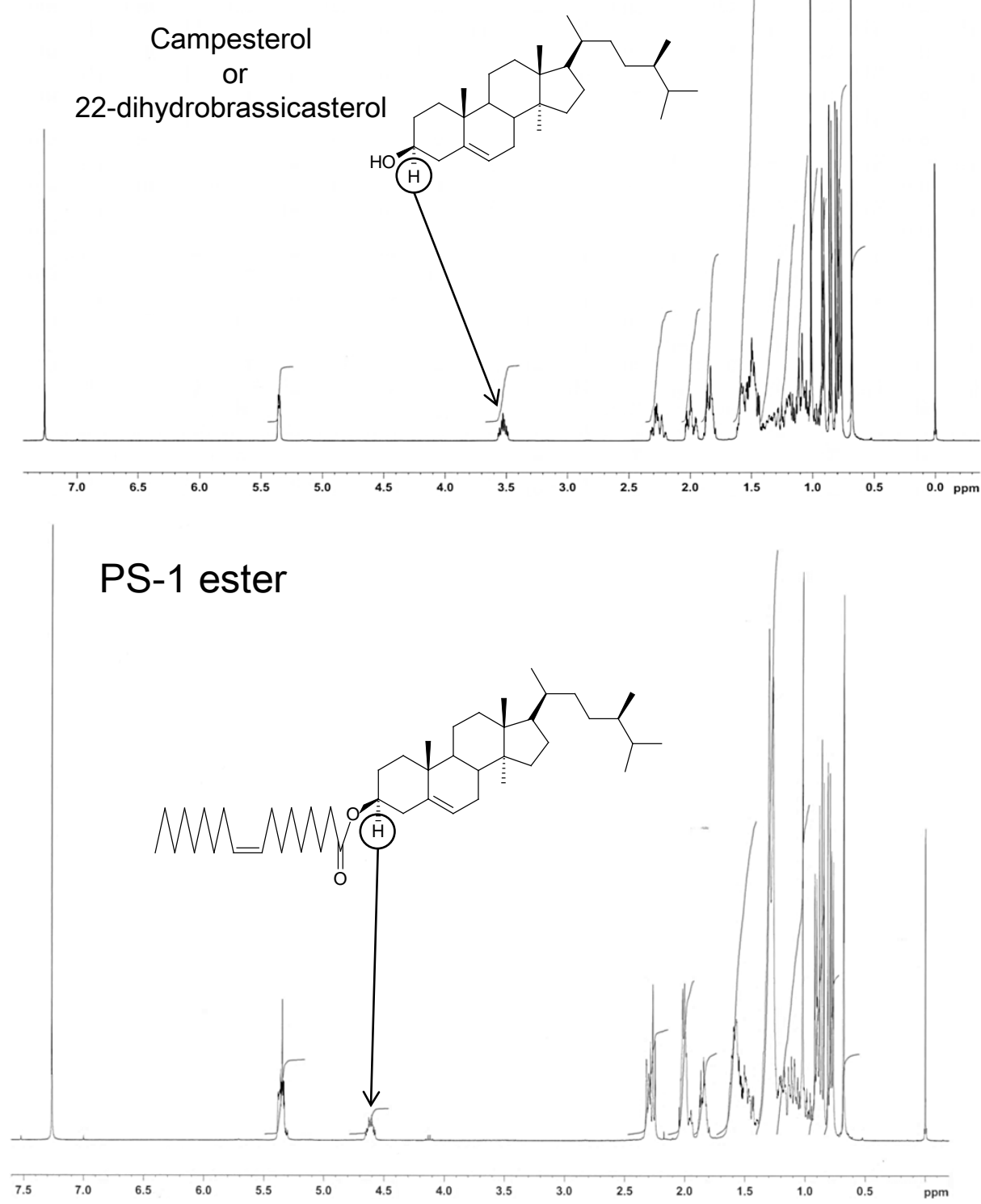

Suppl. fig. 1. ${ }^{1} \mathrm{H}$ NMR spectra of free PS-1 and its oleic acid ester 
Free PS-2

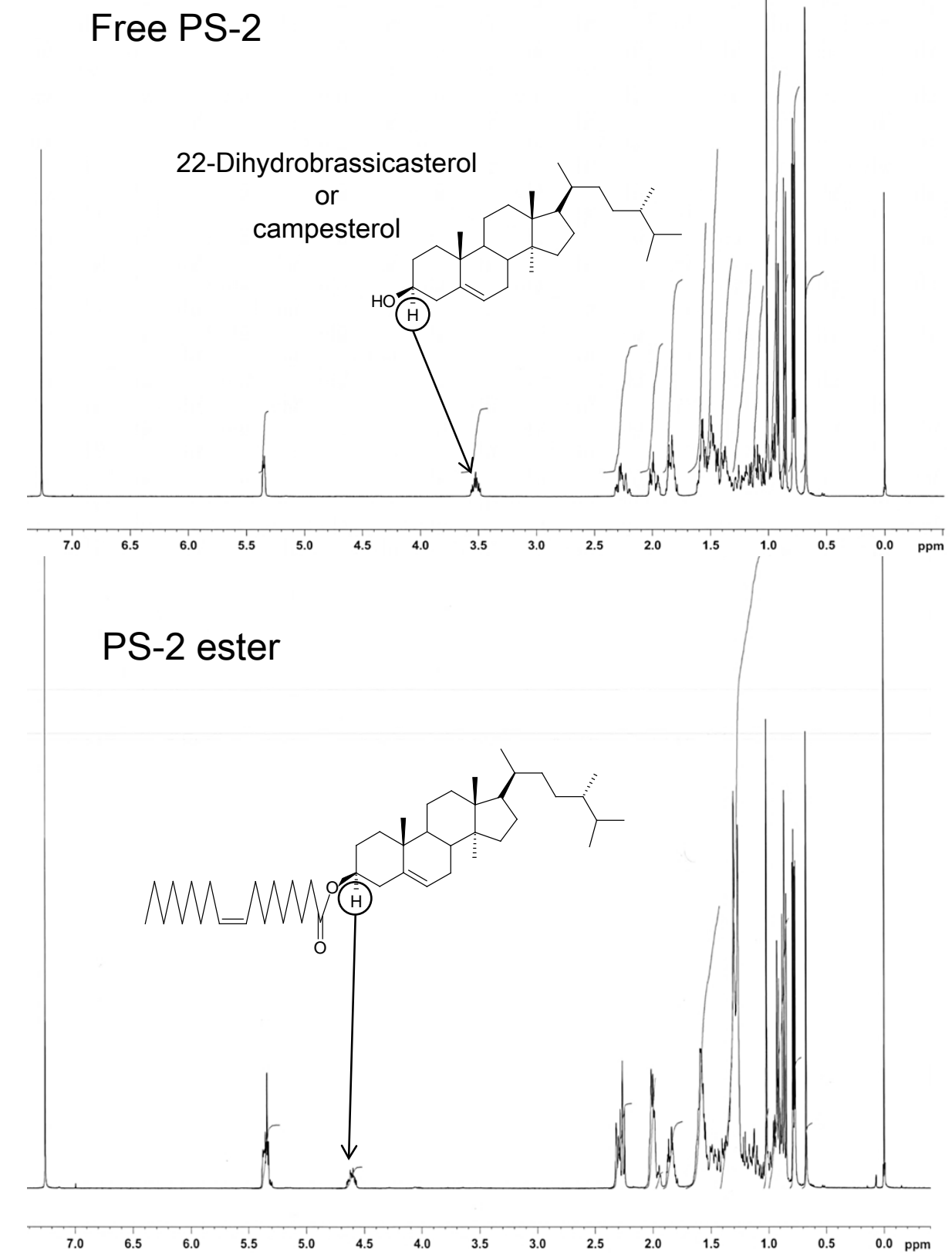

Suppl. fig. 2. ${ }^{1} \mathrm{H}$ NMR spectra of free PS-2 and its oleic acid ester 


\section{Free PS-3}
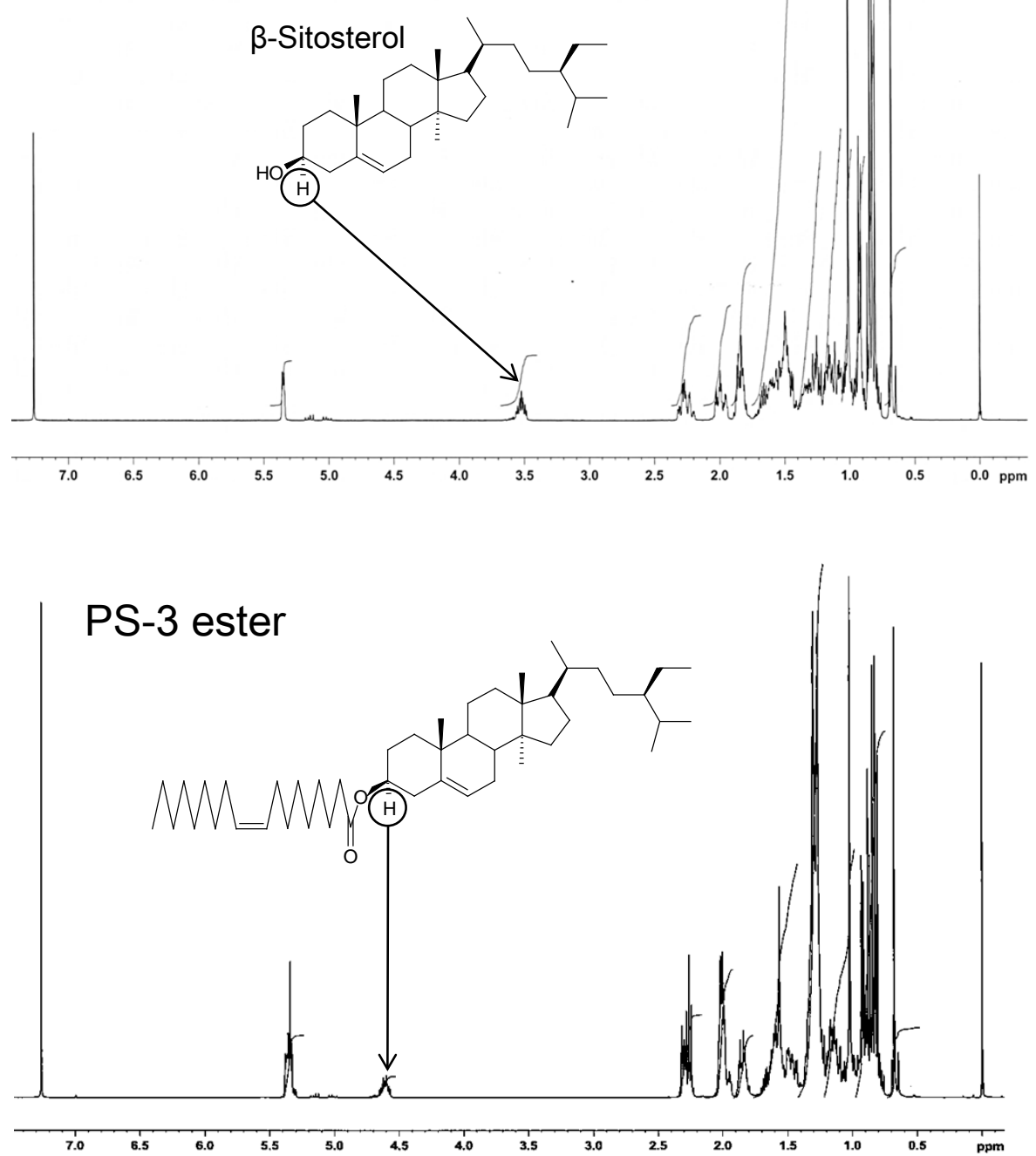

Suppl. fig. 3. ${ }^{1} \mathrm{H}$ NMR spectra of free PS-3 and its oleic acid ester 


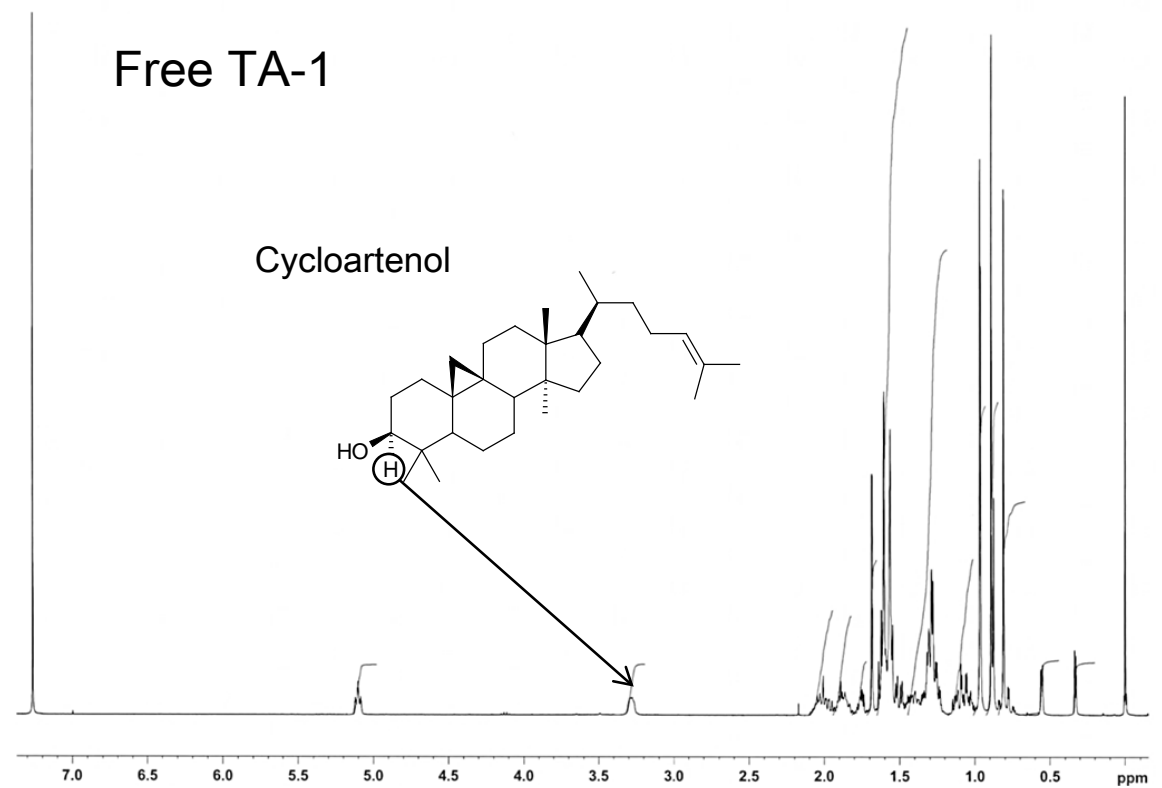

TA-1 ester

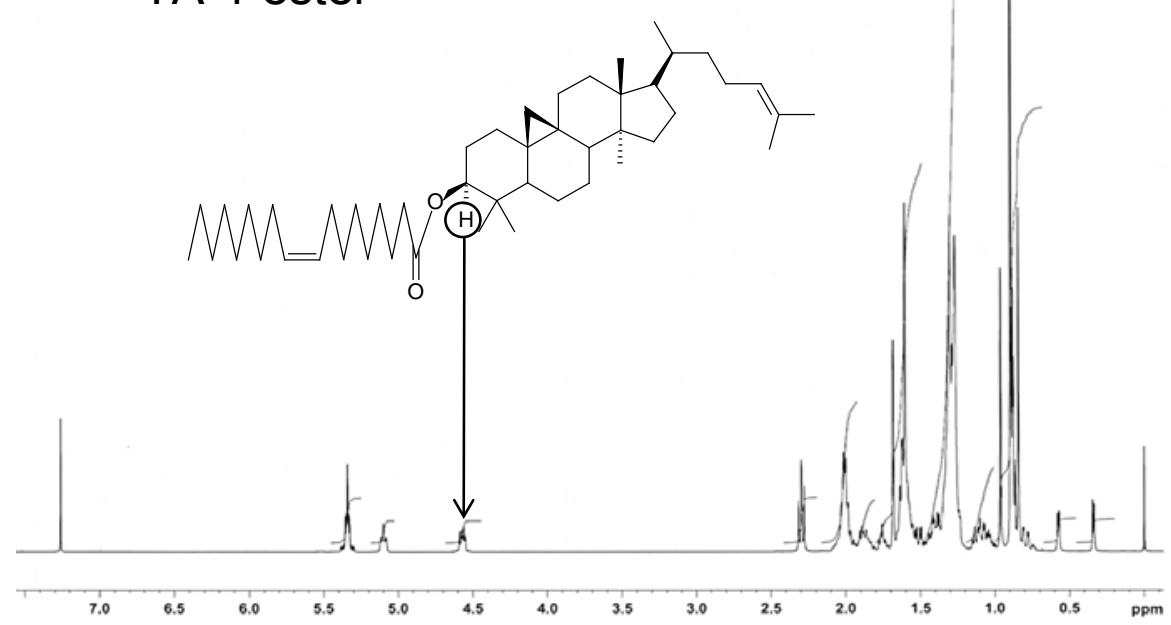

Suppl. fig. 4. ${ }^{1} \mathrm{H}$ NMR spectra of free TA-1 and its oleic acid ester 


\section{Free TA-2}

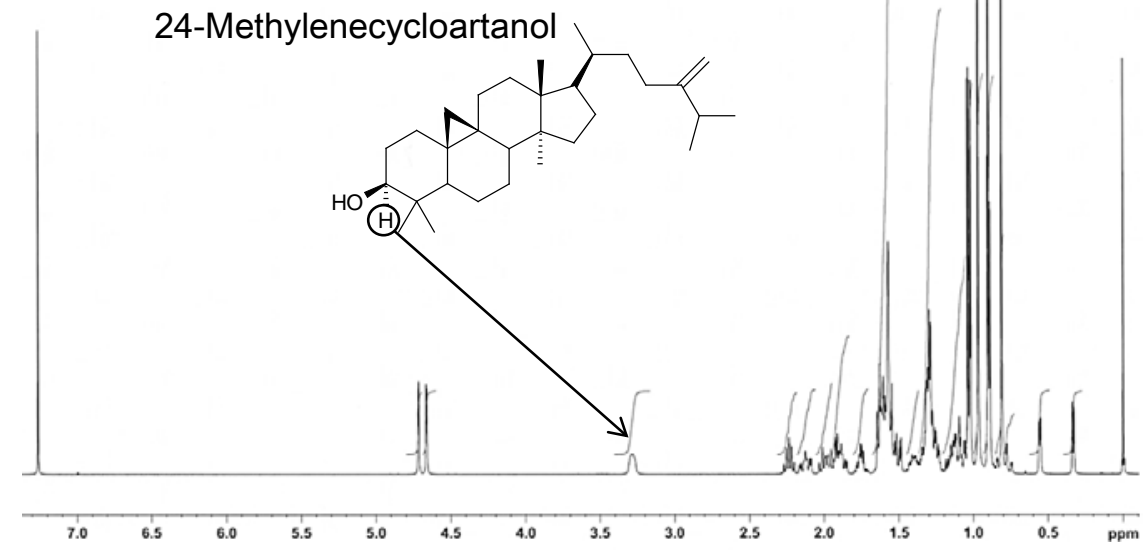

TA-2 ester

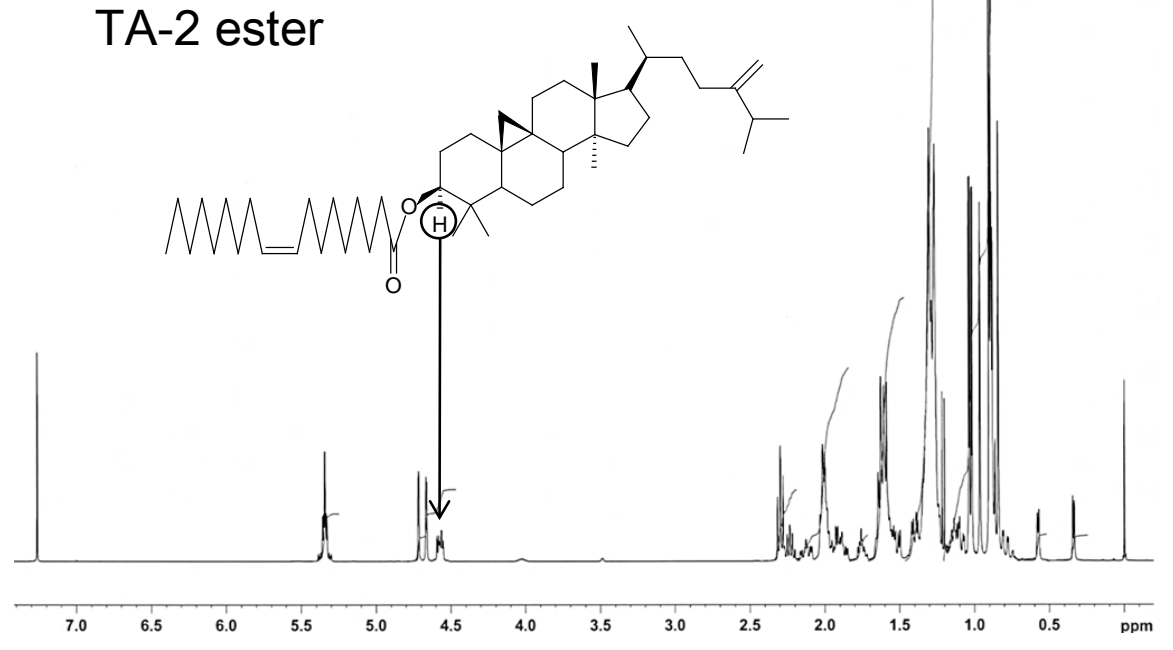

Suppl. fig. 5. ${ }^{1} \mathrm{H}$ NMR spectra of free TA-2 and its oleic acid ester 


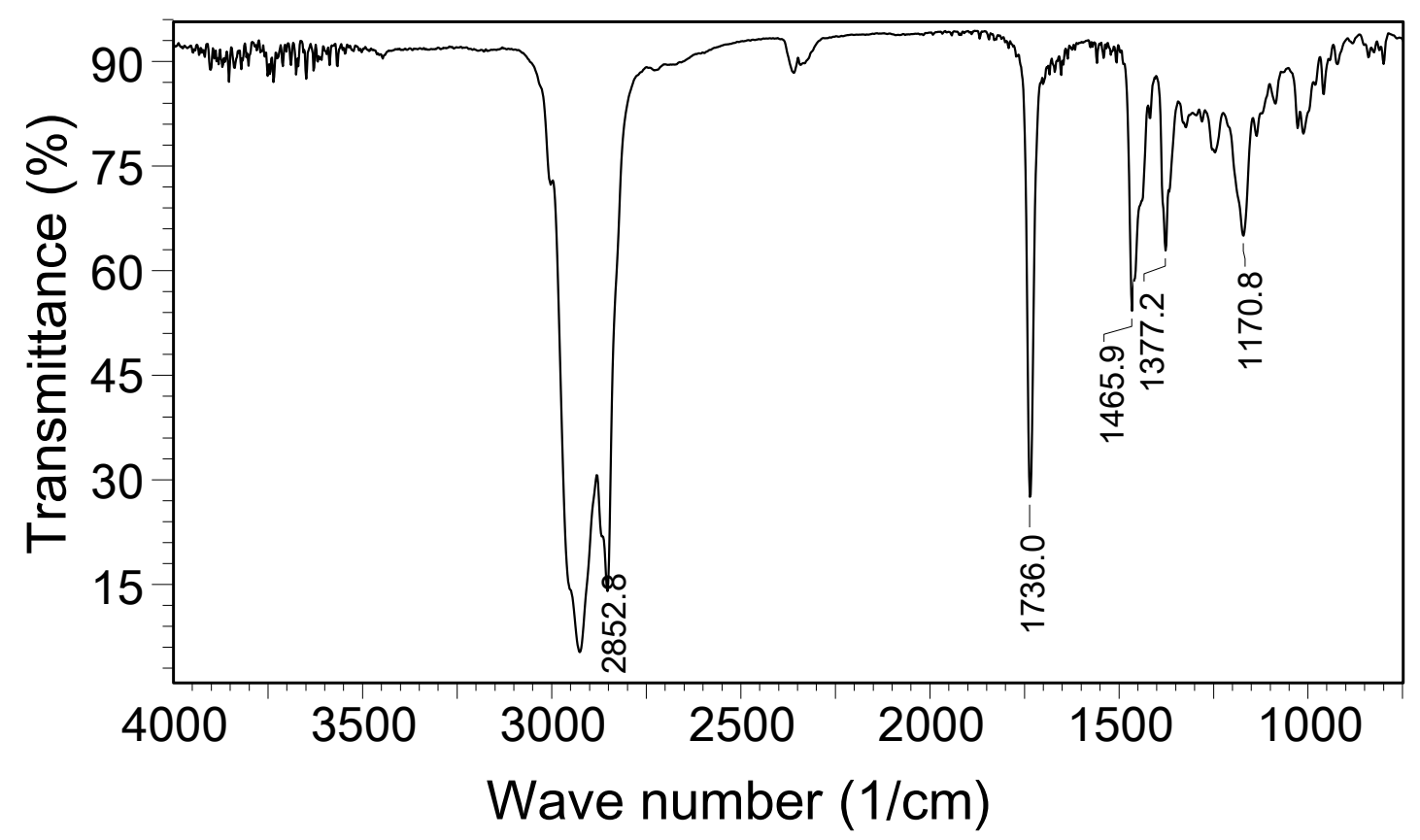

Suppl. fig. 6. IR spectrum of PS-1 oleic acid ester

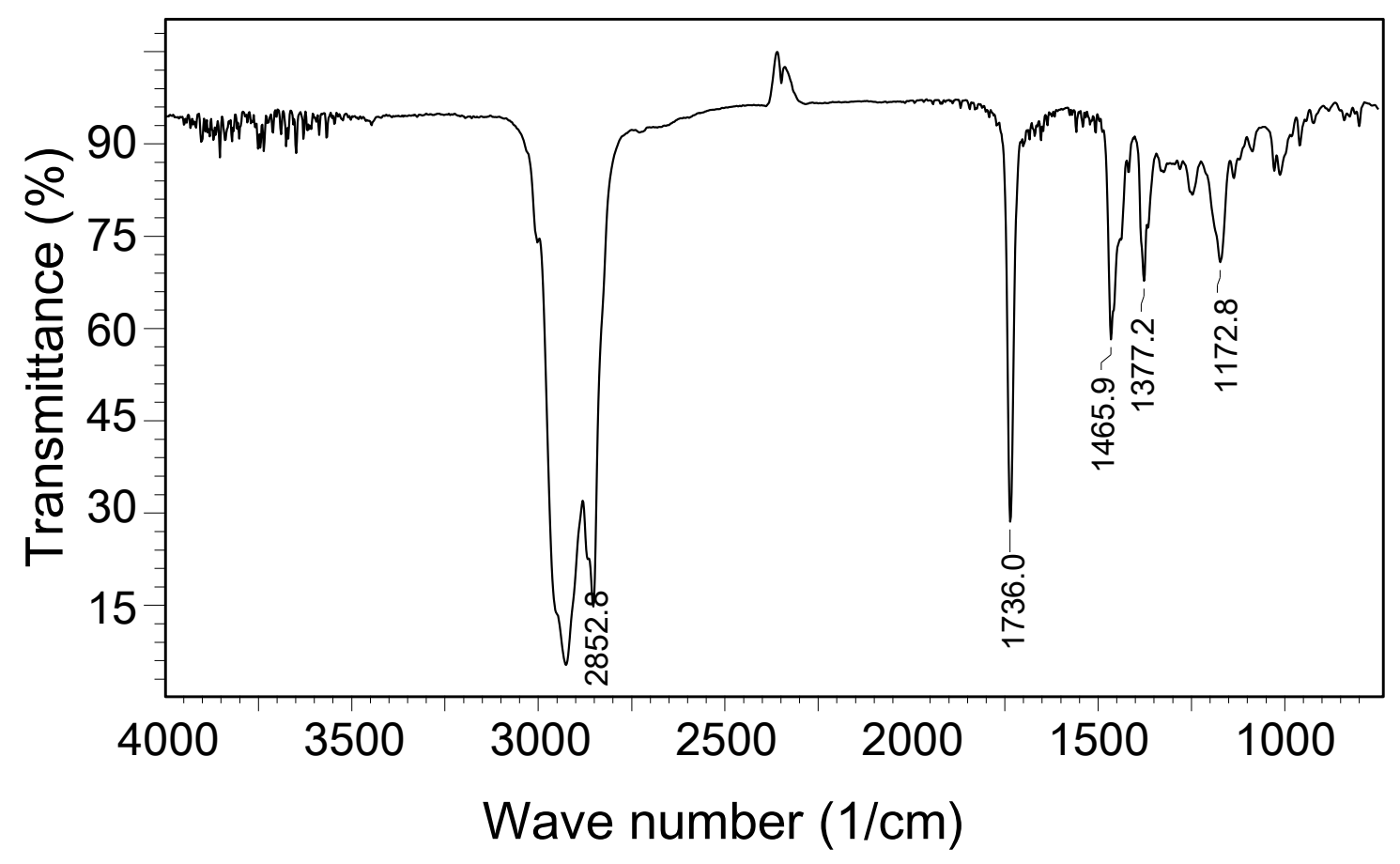

Suppl. fig. 7. IR spectrum of PS-2 oleic acid ester 


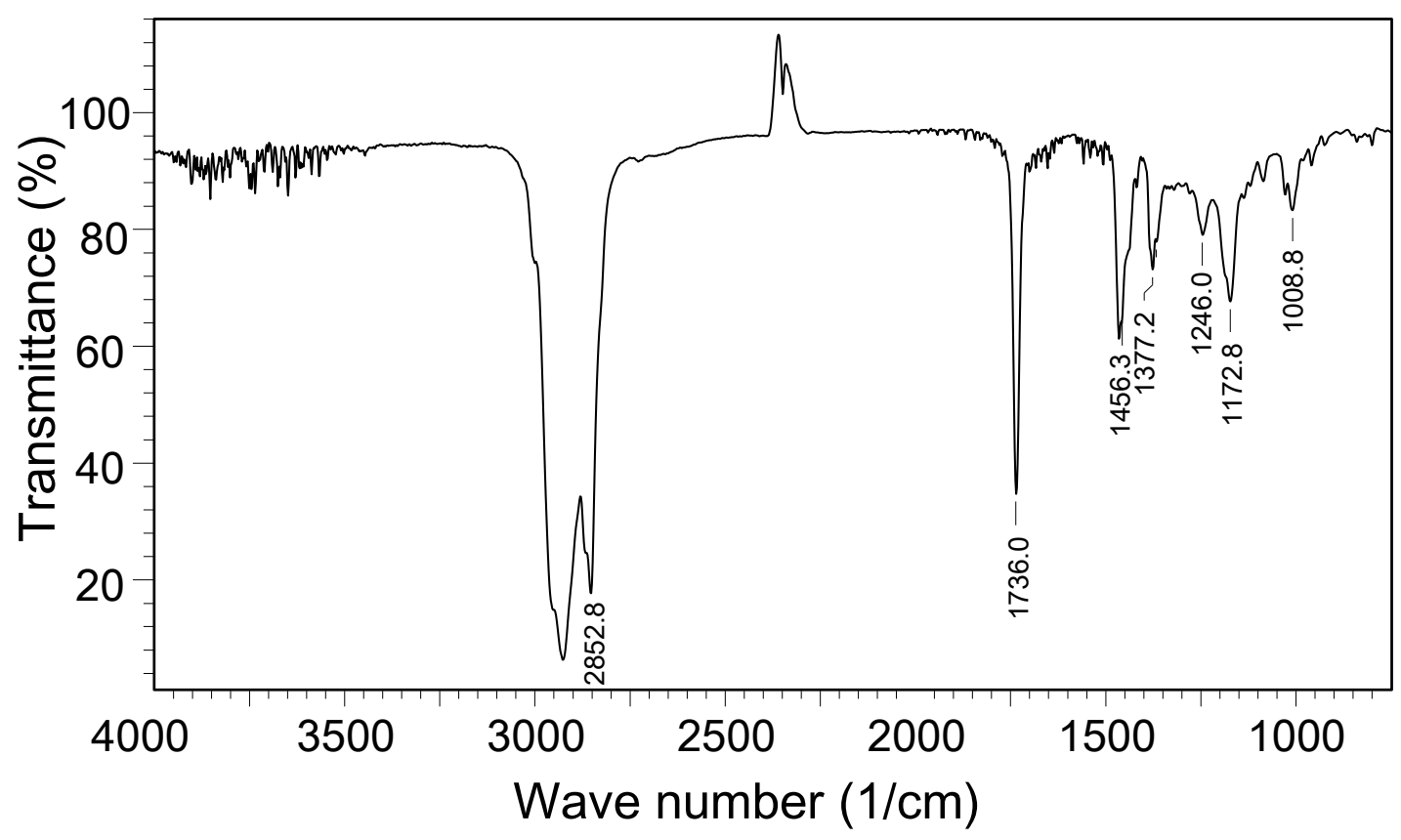

Suppl. fig. 8. IR spectrum of PS-3 oleic acid ester 